\title{
Article \\ Differential Response of the Proteins Involved in Amino Acid Metabolism in Two Saccharomyces cerevisiae Strains during the Second Fermentation in a Sealed Bottle
}

\author{
María del Carmen González-Jiménez ${ }^{1}$, Juan Carlos Mauricio ${ }^{1, *}{ }^{\mathbb{C}}$, Jaime Moreno-García ${ }^{1}{ }^{\mathbb{D}}$, Anna Puig-Pujol ${ }^{2}$, \\ Juan Moreno $^{1}{ }^{1}$ and Teresa García-Martínez ${ }^{1}$ (D) \\ 1 Department of Agricultural Chemistry, Edaphology and Microbiology, Agrifood Campus of International \\ Excellence ceiA3, University of Cordoba, 14014 Cordoba, Spain; b02gojim@uco.es (M.d.C.G.-J.); \\ b62mogaj@uco.es (J.M.-G.); qe1movij@uco.es (J.M.); mi2gamam@uco.es (T.G.-M.) \\ 2 Department of Enological Research, Institute of Agrifood Research and Technology—Catalan Institute of Vine \\ and Wine (IRTA-INCAVI), Vilafranca del Penedès, 08720 Barcelona, Spain; anna.puig@irta.cat \\ * Correspondence: mi1gamaj@uco.es; Tel.: +34-957218640
}

Citation: González-Jiménez, M.d.C.; Mauricio, J.C.; Moreno-García, J.; Puig-Pujol, A.; Moreno, J.; García-Martínez, T. Differential Response of the Proteins Involved in Amino Acid Metabolism in Two Saccharomyces cerevisiae Strains during the Second Fermentation in a Sealed Bottle. Appl. Sci. 2021, 11, 12165. https://doi.org/10.3390/ app112412165

Academic Editor: Maria Kanellaki

Received: 30 September 2021 Accepted: 17 December 2021 Published: 20 December 2021

Publisher's Note: MDPI stays neutral with regard to jurisdictional claims in published maps and institutional affiliations.

Copyright: (c) 2021 by the authors. Licensee MDPI, Basel, Switzerland. This article is an open access article distributed under the terms and conditions of the Creative Commons Attribution (CC BY) license (https:// creativecommons.org/licenses/by/ $4.0 /)$.

\begin{abstract}
The traditional method for sparkling wine making consists of a second fermentation of a base wine followed by ageing in the same bottle that reaches the consumers. Nitrogen metabolism is the second most important process after carbon and takes place during wine fermentation by yeast. Amino acids are the most numerous nitrogen compounds released by this process. They contribute to the organoleptic properties of the wines and, therefore, to their sensory quality. The main objective of this study is to compare the differential proteomic response of amino acid metabolism, specifically their proteins and their interactions in the G1 strain (unconventional yeast) during sparkling wine production versus the conventional P29 strain. One of the new trends in winemaking is the improvement of the organoleptic diversity of wine. We propose the use of unconventional yeast that shows desirable characteristics for the industry. For this purpose, these two yeasts were grown at sealed bottle conditions for the second fermentation (Champenoise method). No differences were obtained in the middle of fermentation between the yeast strains. The number of proteins identified, and the relationships established, were similar, highlighting lysine metabolism. At the end of the second fermentation, the difference between each strain was remarkable. Hardly any proteins were identified in unconventional versus conventional yeast. However, in both strains, the metabolism of sulfur amino acids, methionine, and cysteine obtained a greater number of proteins involved in these processes. The release of these amino acids to the medium would allow the yeast to balance the internal redox potential by reoxidation of NADPH. This study is focused on the search for a more complete knowledge of yeast metabolism, specifically the metabolism of amino acids, which are key compounds during the second fermentation.
\end{abstract}

Keywords: sparkling wine; protein; interact omics; amino acid metabolism; yeast; GO terms

\section{Introduction}

"Méthode champenoise", also known as the traditional method, is a sparkling wine production method whereby wine undergoes a second fermentation process in the bottle to produce $\mathrm{CO}_{2}$. During the aging of sparkling wines in contact with the yeast lees, the phenomenon of autolysis takes place. Through this process, nitrogen compounds are released that contribute to the organoleptic properties of the wines and therefore to their sensory quality.

Nitrogen is a key nutrient vital to yeast during wine fermentation, and its availability in grape is a key parameter for the progress of wine fermentation, affecting both fermentation kinetics and wine aroma formation. The shortage of these compounds can cause slow or stuck fermentations $[1,2]$ or influence the formation of reduced sulfur compounds, such 
as hydrogen sulfide [3]. Furthermore, the catabolism of nitrogen sources and the central metabolism of carbon is involved in the synthesis of fermentative aroma precursors in oenological yeasts $[4,5]$.

Saccharomyces cerevisiae can grow on a wide variety of nitrogenous substrates; the metabolism of nitrogenous compounds depends on the yeast strain, its physiological state, and the physicochemical properties of the wine. Nitrogen metabolism is controlled by regulatory mechanisms that depend largely on the nature of the nitrogen sources present in the wine. These mechanisms act at the transcriptional level, as well as in the activity and degradation of enzymes and permeases [6]. The assimilable fraction of nitrogen by yeasts is mainly ammonia and amino acids in similar proportions, but they can also use other nitrogen sources, such as oligopeptides, polypeptides, proteins, amides, biogenic amines, and nucleic acids $[7,8]$. S. cerevisiae incorporates amino acids and small peptides (less than five amino acid residues) through an active transport process using specialized membrane proteins and a $\mathrm{pH}$ gradient $[6,9]$. The amount of these compounds in sparkling wines depends on the grape variety and the aging time $[7,8]$. To cope with these stressful conditions, which can cause nitrogen shortages, yeasts consume and metabolize these compounds as efficiently as possible during fermentation. The preferred compound for yeast is glutamate, which is stored for de novo amino acid biosynthesis. This is particularly relevant when the ethanol content increases, which inhibits amino acid absorption [9]. S. cerevisiae uses amino acids differentially; preferred nitrogen sources are alanine, arginine, asparagine, aspartate, glutamate, glutamine, and serine [7].

The amino acids present in sparkling wines have different origins: (i) they can come directly from the grape, without being metabolized by yeast during its growth, (ii) they can excrete at the end of fermentation, (iii) and they can also originate during the autolysis process. Generally, these amino acids are used by yeast for the formation of proteins or as a source of nitrogen by oxidative deamination; alternatively, an amino acid can be broken down and thus liberate nitrogen. During fermentation, yeast incorporates and metabolizes amino acids to grow and produce biomass. In this process, a series of volatile aromatic compounds are produced (esters, higher alcohols, volatile fatty acids, carbonyls, and sulfur compounds), which have a great impact on the organoleptic properties of wines. In addition, the nitrogen released can also be used for the biosynthesis of other nitrogenous cellular constituents, and its carbon structure can be excreted in wine or used as a carbon source for the biosynthesis of other compounds, such as higher alcohols [10,11], which constitute the main group of aromatic compounds in wine [7]. Nitrogen metabolism is very complex because its intermediaries are also shared among other metabolic pathways. Because of this, there is not yet a complete understanding of the impact of amino acids on the formation of different aromatic compounds.

Therefore, it is important to establish a fundamental dataset in order to build solid knowledge. This new study, along with the rest of the work carried out by our research group, seeks to address the lack of information that exists in multi-omics analysis by integrating the proteomics and metabolomics of $S$. cerevisiae during the second fermentation in the production of sparkling wines (cava). For this reason, in previous works, our research group has focused on the study of ester metabolism [12] and the autophagy process [13], as well as the effect of $\mathrm{CO}_{2}$ overpressure on the aroma [14,15] during the second fermentation in the production of sparkling wines (cava). In addition, the novelty of using an unconventional yeast for the production of this type of wine was introduced. It is a flor yeast that, due to properties such as its high tolerance to ethanol and its flocculation capacity, could be a good candidate for use in the production of sparkling wine. In this way, the diversity, uniqueness, and typicality of sparkling wine yeasts could be improved.

The main objective of this study was to compare the differential proteomic response of amino acid metabolism, specifically their proteins and their interactions in the G1 strain (unconventional yeast) during sparkling wine production versus the conventional P29 strain. This relationship never been investigated before in sparkling wines, hence the 
difficulty of this study and the relevance of its results. This knowledge is intended to serve as a guide for future research and ultimately to improve the quality of the wine.

\section{Materials and Methods}

\subsection{Microorganisms and Fermentation Conditions}

The microorganisms used were two strains of S. cerevisiae: the conventional P29 strain (CECT11770), a typical yeast in the production of sparkling wines, which was isolated from the designation of origin of the Penedès (DO) Barcelona (Northeast of Spain), and the G1 strain (ATCC: MYA-2451). The G1 strain is a flor yeast isolated from a flor "velum" under the biological aging of "Fino" Sherry wine of the designation of origin (DO) MontillaMoriles in Córdoba (Southern of Spain).

The yeast strains were incubated for 5 days at $21^{\circ} \mathrm{C}$ using a gentle agitation of $100 \mathrm{rpm}$ for their growth in a pasteurized must of Macabeo grape variety, composed of $174.9 \mathrm{~g} / \mathrm{L}$ of sugar, $18.5^{\circ} \mathrm{Bx}, 3.6 \mathrm{~g} / \mathrm{L}$ of total acidity, and $3.43 \mathrm{pH}$. When an ethanol content of $10.39 \%(v / v)$ was reached, the yeast cells were introduced into bottles with a standardized commercial base wine (Macabeo: Chardonnay (6:4), 10.21\% $(v / v)$ of ethanol, $0.3 \mathrm{~g} / \mathrm{L}$ of sugar, $\mathrm{pH} 3.29,5.4 \mathrm{~g} / \mathrm{L}$ of total acidity, and $0.21 \mathrm{~g} / \mathrm{L}$ of volatile acidity), $21 \mathrm{~g} / \mathrm{L}$ sucrose, and $1.5 \times 10^{6}$ cells $/ \mathrm{mL}$. The second fermentation was carried out in a thermostatic chamber at $14{ }^{\circ} \mathrm{C}$ in bottles with a volume of $750 \mathrm{~mL}$. During the second fermentation, the following samples were taken: at the middle of the second fermentation, MF ( 3 bar pressure), and at the end of the second fermentation, EF ( 6.5 bar pressure). In each sample, three bottles were opened for triplicate analysis.

Viable yeast cell counting was carried out using appropriate dilutions with Ringer solution. These were then plated in Sabouraud agar medium for $48 \mathrm{~h}$ at $28{ }^{\circ} \mathrm{C}$, and all samples were analyzed five-fold.

\subsection{Proteomic Analysis}

Cells were collected from each bottle by centrifugation at $4500 \times \mathrm{g}$ for $10 \mathrm{~min}$ using a centrifuge (Rotina-38, Kirchlengern, Germany), washing the pellet twice with cold sterile distilled water. Subsequently, the washed cell pellets were dissolved in $2 \mathrm{~mL}$ extraction buffer (100 mM Tris-HCl pH 8, $0.1 \mathrm{mM}$ EDTA, $2 \mathrm{mM}$ DTT and $1 \mathrm{mM}$ PMSF) and a protease inhibitor cocktail. Lysis of cells was performed using a mechanical technique in a Vibrogen Cell Mill V6 (Edmund Bühler GmbH, Bodelshausen, Germany) using glass beads of $500 \mu \mathrm{m}$ in diameter. Once the cells were disrupted, the protein extraction was removed. Glass beads as well as cell debris were discarded by centrifugation at $500 \times g$ for $5 \mathrm{~min}$. Protein precipitation was carried out by overnight incubation at $-20{ }^{\circ} \mathrm{C}$ after the addition of $10 \%$ $w / v$ of trichloroacetic acid (TCA) and 4 vol of ice-cold acetone to the supernatant. After incubation, samples were centrifuged at $16,000 \times g$ for $30 \mathrm{~min}$, and the protein pellet was then vacuum dried and resuspended in solubilization buffer. Protein concentration was estimated by Bradford (1976) and samples stored at $-80^{\circ} \mathrm{C}$ until protein analysis [16]. To perform this analysis, $500 \mu \mathrm{g}$ of total protein for each condition and replica was loaded into an Agilent Technologies OFFGEL 3100 fractionator well tray. Previously, protein samples were solubilized in a Protein OFFGEL fractionation buffer containing urea, thiourea, DTT, glycerol, and ampholytic buffer. The aliquots were distributed in an Agilent Technologies OFFGEL 3100 fractionator (Santa Clara, CA, USA), in a tray with wells. Once the proteins were separated according to their isoelectric point, the fractions were collected from each well and their identification was carried out. For identification, protein fractions were analyzed on an LTQ Orbitrap XL mass spectrometer equipped with an Ultimate 3000 nano LC system at the Central Research Support Service (SCAI) of the University of Córdoba. Proteins had to be digested with trypsin beforehand. Finally, the identified proteins were quantified following the exponentially modified Protein Abundance Index, EmPAI, a method described by Ishihama et al. (2005) [17]. More detailed information is described in articles published by the research group [12]. 


\subsection{Statistical Analysis}

After identification, the proteins were filtered to take into account those involved in "amino acid metabolism", according to the Gene Ontology terminology (GO) of the Saccharomyces genome database (https: / / www.yeastgenome.org/, accessed on 15 February 2021), using the GO Slim Mapper tool. The selected processes were: (i) cellular amino acid metabolic process, (ii) amino acid transport, (iii) tRNA aminoacylation for protein translation.

The proteins involved in the "cellular amino acid metabolic process" were classified in different GO terms provided by the SGD database (https: / /www.yeastgenome.org/, accessed on 15 February 2021). This classification was made using the GO Term Finder tool, provided by the database. The GO terms are descriptive terms that allow relating each gene product with a molecular, cellular, and biological process context, providing a statistical value ( $p$-value). This statistical study was performed with a level of significance $(\alpha)$ of 0.05 .

The proteins discussed in this study were strain-specific proteins during the second fermentation in bottle.

\subsection{Protein Network Reconstruction}

The software STRING version 11 (available online, https:/ / string-db.org/, accessed on 15 February 2021) was used to reconstruct an interaction network for proteins of interest, forming specific protein groups through an MCL (Markov Cluster Algorithm) clustering method. This algorithm accepts a parameter called 'inflation' that is indirectly related to the precision of the clustering. Data were previously normalized through the root square and auto-scaling methods [18].

\section{Results and Discussion}

The present study was carried out on two strains of $S$. cerevisiae: a conventional strain for the elaboration of this type of wine (P29 strain) and a non-conventional yeast (G1 strain) under real conditions of the second fermentation; the sample times were at the middle of the second fermentation (MF) and at the end of the second fermentation in a sealed bottle (EF).

For this, the total proteins identified in each strain were compared, and those different in each case were selected (from now on named as specific). They were then classified into three processes (amino acid transport, tRNA aminoacylation for protein translation, and cellular metabolism) according to the Saccharomyces Genome Database (SGD). Data are shown in Table 1. Finally, the proteins involved in the cellular metabolism process were classified in GO terms according to the SGD database, and the interactions between them were established using STRING software.

Table 1. Biological processes, specific proteins, and ratio of specific to the total proteins related to amino acid metabolism in S. cerevisiae P29 and G1 during two sampling times, at the middle of the second fermentation (MF) and at the end of the second fermentation $(\mathrm{EF})$.

\begin{tabular}{|c|c|c|c|c|}
\hline \multirow[b]{3}{*}{ Biological Process } & \multicolumn{4}{|c|}{ Middle of the Second Fermentation, MF } \\
\hline & \multicolumn{2}{|l|}{ P29 Strain } & \multicolumn{2}{|l|}{ G1 Strain } \\
\hline & Specific Proteins & $\begin{array}{l}\text { Specific/Total } \\
\text { Proteins }\end{array}$ & Specific Proteins & $\begin{array}{c}\text { Specific/Total } \\
\text { Proteins }\end{array}$ \\
\hline $\begin{array}{l}\text { Cellular amino acid } \\
\text { metabolic process } \\
\text { (GO: 0006520) }\end{array}$ & $\begin{array}{c}\text { Aat1p, Ald2p, Arg81p, Aro9p, } \\
\text { Dal81p, Gcv2p, Gdh3p, Ilv6p, } \\
\text { Leu9p, Lys1p, Lys4p, Met1p, } \\
\text { Mis1p, Put1p, Snz3p, Ths1p, } \\
\text { Uga2p, Uga3p, Ura7p, Utr4p, } \\
\text { Xbp1p, Ydl168wp, } \\
\text { Yml082wp, Ymr084wp }\end{array}$ & $24 / 103$ & $\begin{array}{l}\text { Aco2p, Adi1p, Aro10p, Bna4p, } \\
\text { Cpa2p, Ehd3p, Gcv1p, Gfa1p, } \\
\text { Gln4p, Gly1p, His5p, Idp1p, } \\
\text { Lap3p, Lys21p, Mae1p, Met12p, } \\
\text { Met16p, Mri1p, Nit3p, Pet112p, } \\
\text { Ser1p, Sfa1p, Sno3p, Tum1p, } \\
\text { Uga1p, Yhr112cp, } \\
\text { Yhr208wp, Yll058wp }\end{array}$ & $28 / 107$ \\
\hline
\end{tabular}


Table 1. Cont.

\begin{tabular}{|c|c|c|c|c|}
\hline \multirow[b]{3}{*}{ Biological Process } & \multicolumn{4}{|c|}{ Middle of the Second Fermentation, MF } \\
\hline & \multicolumn{2}{|c|}{ P29 Strain } & \multicolumn{2}{|l|}{ G1 Strain } \\
\hline & Specific Proteins & $\begin{array}{l}\text { Specific/Total } \\
\text { Proteins }\end{array}$ & Specific Proteins & $\begin{array}{l}\text { Specific/Total } \\
\text { Proteins }\end{array}$ \\
\hline $\begin{array}{l}\text { tRNA aminoacylation } \\
\text { for protein translation } \\
\text { (GO: 0006418) }\end{array}$ & $\begin{array}{c}\text { Aim10p, Cdc60p, Ded81p, } \\
\text { Dia4p, Dps1p, Msk1p, Slm5p, } \\
\text { Ths1p, Wrs1p }\end{array}$ & $9 / 23$ & Gln $4 p$, Nam2p & $2 / 16$ \\
\hline \multirow[t]{3}{*}{$\begin{array}{l}\text { Amino acid transport } \\
\text { (GO: 0006865) }\end{array}$} & $\begin{array}{l}\text { Avt7p, Bap2p, Lst4p, Put4p, } \\
\text { Uga4p, Ydl119cp }\end{array}$ & $6 / 9$ & $\begin{array}{l}\text { Alp1p, Avt4p, Btn2p, } \\
\text { Gnp1p, Ssy1p }\end{array}$ & $5 / 8$ \\
\hline & \multicolumn{4}{|c|}{ End of the second fermentation, EF } \\
\hline & \multicolumn{2}{|l|}{ P29 Strain } & \multicolumn{2}{|l|}{ G1 Strain } \\
\hline Biological Process & Specific Proteins & $\begin{array}{l}\text { Specific/Total } \\
\text { Proteins }\end{array}$ & Specific Proteins & $\begin{array}{l}\text { Specific/Total } \\
\text { Proteins }\end{array}$ \\
\hline $\begin{array}{l}\text { Cellular amino acid } \\
\text { metabolic process } \\
\text { (GO: 0006520) }\end{array}$ & $\begin{array}{l}\text { Ade3p, Adh3p, Arg1p, Arg7p, } \\
\text { Arg8p, Arg80p, Arg82p, Aro1p, } \\
\text { Aro2p, Aro3p, Asn1p, Asn2p, } \\
\text { Bna1p, Car1p, Car2p, Cys3p, } \\
\text { Cys4p, Dtd1p, Gdh1p, Gln1p, } \\
\text { Gus1p, His4p, Hom6p, Hpa3p, } \\
\text { Idh1p, Ilv6p, Kgd2p, Leu4p, } \\
\text { Lpd1p, Lys12p, Lys20p, Mcm1p, } \\
\text { Met17p, Mis1p, Mmf1p, Pro2p, } \\
\text { Sam2p, Ser1p, Ser3p, Sfa1p, } \\
\text { Shm2p, Uga1p, Yhr208wp }\end{array}$ & $43 / 56$ & $\begin{array}{l}\text { Gcv3p, Gfa1p, Idh2p, Idp1p, } \\
\text { Met13p, Met8p, Sno3p, } \\
\text { Snz1p, Ybr145wp }\end{array}$ & $9 / 22$ \\
\hline $\begin{array}{l}\text { tRNA aminoacylation } \\
\text { for protein translation } \\
\text { (GO: 0006418) }\end{array}$ & $\begin{array}{l}\text { Arc1p, Grs1p, Gus1p, Ism1p, } \\
\text { Msk1p, Ses1p, Vas1p }\end{array}$ & $7 / 8$ & Msm1p & $1 / 2$ \\
\hline $\begin{array}{l}\text { Amino acid transport } \\
\text { (GO: 0006865) }\end{array}$ & Npr2p & $1 / 1$ & & \\
\hline
\end{tabular}

\subsection{Amino Acid Transport}

Amino acids are involved in numerous metabolic pathways. S. cerevisiae can synthesize them de novo; they are also actively imported from the extracellular environment. This is less expensive in terms of energy; the estimated cost of de novo amino acid synthesis under aerobic conditions is between 9.5 ATP for glutamate and 75.5 ATP for tryptophan [19]. Yeast export of amino acids enables them to respond to different environments and take advantage of available resources. The amino acids present in the vacuole are histidine, lysine, and arginine, constituting 80 to $90 \%$, while a similar fraction of glutamate and aspartate is present in the cytosol [20-22]. S. cerevisiae incorporates amino acids from the medium, making use of proteins known as amino acids permeases by a simport mechanism [23]. The multiplicity and diversity of transporters allows yeast to accumulate amino acids for biosynthesis and catabolism under multiple conditions and in a wide range of external concentrations [24].

Of the total transporters identified in S. cerevisiae (41 transporters) [19], 6 transporters (Avt7p, Bap2p, Lst4p, Put4p, Uga4p, Ydl119cp) in MF and 1 (Npr2p) in EF have been obtained in the P29 strain. While in the G1 strain, 5 (Alp1p, Avt4p, Btn2p, Gnp1p, Ssy1p) in MF and 0 in EF have been reported. In view of these results, it would not be expected to find a great difference between the two strains. However, the transporters identified in both types of yeast were different, although all transport the full range of amino acids from the cell exterior to the interior and from the cell interior to the vacuole or mitochondria.

Of the transporters identified in the P29 strain, Avt7p was the one with the highest protein content $(0.028 \mathrm{~mol} \%)$. Data are shown in Table 2. Yeast Avtp proteins can be subdivided into four main groups, defined as Avt1p, Avt2p, Avt3p/4p, and Avt5p/6p/7p [25]. Avt1p intervenes in the active absorption of amino acids in the vacuole, while Avt3p, Avt $4 p$, and Avt6p are involved in the active exit of amino acids from the vacuole into the 
cytosol. Avt7p is located in the vacuolar membrane of S. cerevisiae and participates in the vacuolar absorption of glutamine and proline and in the formation of spores in S. cerevisiae, which could be related to the Avt7p-dependent amino acid flux of vacuoles under the conditions of lack of nutrients [26]. On the other hand, the protein that had the highest protein content in the G1 yeast was Btn2p $(0.022 \mathrm{~mol} \%)$; this protein participates in the uptake of arginine [27].

Table 2. Quantification of specific proteins identified in each strain using the EmPAI method (mol\%) in S. cerevisiae P29 and G1 during two sampling times: at the middle of the second fermentation (MF) and at the end of the second fermentation (EF).

\begin{tabular}{|c|c|c|c|c|c|c|c|c|c|c|c|}
\hline \multicolumn{6}{|c|}{ MF } & \multicolumn{6}{|c|}{ EF } \\
\hline \multicolumn{3}{|c|}{ P29 Strain } & \multicolumn{3}{|c|}{ G1 Strain } & \multicolumn{3}{|c|}{ P29 Strain } & \multicolumn{3}{|c|}{ G1 Strain } \\
\hline Proteins & $\mathrm{mol} \%$ & SD & Proteins & $\mathrm{mol} \%$ & SD & Proteins & $\mathrm{mol} \%$ & SD & Proteins & $\mathrm{mol} \%$ & SD \\
\hline Aat1p & 0.024 & 0.0002 & Aco2p & 0.028 & 0.0003 & Ade $3 p$ & 0.007 & 0.0001 & Gcv3p & 0.427 & 0.004 \\
\hline $\operatorname{Ald} 2 \mathrm{p}$ & 0.010 & 0.0001 & Adilp & 0.048 & 0.0005 & Adh3p & 0.078 & 0.0008 & Gfa1p & 0.033 & 0.0008 \\
\hline Arg81p & 0.006 & 0.0001 & Aro10p & 0.010 & 0.0001 & Arg1p & 0.114 & 0.0011 & $\operatorname{Idh} 2 \mathrm{p}$ & 0.081 & 0.001 \\
\hline Aro9p & 0.028 & 0.0003 & Bna4p & 0.010 & 0.0001 & Arg7p & 0.055 & 0.0006 & Idp1p & 0.0465 & 0.0005 \\
\hline Dal81p & 0.007 & 0.0001 & Cpa2p & 0.028 & 0.0003 & Arg8p & 0.013 & 0.0001 & Met13p & 0.051 & 0.001 \\
\hline Gcv2p & 0.005 & 0.0001 & Ehd3p & 0.011 & 0.0001 & Arg80p & 0.039 & 0.0004 & Met8p & 0.069 & 0.0007 \\
\hline Gdh3p & 0.057 & 0.0006 & Gcv1p & 0.013 & 0.0001 & Arg82p & 0.0187 & 0.0002 & Sno3p & 0.106 & 0.0011 \\
\hline Ilv6p & 0.016 & 0.0002 & Gfa1p & 0.015 & 0.0001 & Arolp & 0.004 & 0.0000 & Snz1p & 0.076 & 0.0006 \\
\hline Leu9p & 0.048 & 0.0005 & $G \ln 4 p$ & 0.005 & 0.0003 & Aro2p & 0.150 & 0.0015 & & & \\
\hline Lys1p & 0.052 & 0.0005 & Gly1p & 0.108 & 0.0011 & Aro3p & 0.276 & 0.0028 & & & \\
\hline Lys4p & 0.015 & 0.003 & His5p & 0.060 & 0.0006 & Asn1p & 0.082 & 0.0008 & & & \\
\hline Met1p & 0.015 & 0.0001 & Idp1p & 0.031 & 0.0003 & Asn2p & 0.036 & 0.0004 & & & \\
\hline Mis1p & 0.005 & 0.0000 & Lap3p & 0.046 & 0.0005 & Bna1p & 0.039 & 0.0004 & & & \\
\hline Put1p & 0.011 & 0.0001 & Lys21p & 0.138 & 0.0014 & Car1p & 0.134 & 0.0013 & & & \\
\hline Snz3p & 0.016 & 0.0002 & Mae1p & 0.016 & 0.0002 & Car2p & 0.055 & 0.0006 & & & \\
\hline Ths1p & 0.011 & 0.0001 & Met12p & 0.017 & 0.0002 & Cys3p & 0.113 & 0.0011 & & & \\
\hline Uga2p & 0.011 & 0.0001 & Met16p & 0.022 & 0.0002 & Cys4p & 0.131 & 0.0013 & & & \\
\hline Uga3p & 0.010 & 0.0001 & Mri1p & 0.014 & 0.0001 & Dtd1p & 0.114 & 0.0011 & & & \\
\hline Ura7p & 0.017 & 0.0002 & Nit3p & 0.016 & 0.0002 & Gdh1p & 0.139 & 0.0014 & & & \\
\hline Utr4p & 0.029 & 0.0003 & Pet112p & 0.009 & 0.0005 & $\mathrm{G} \ln 1 \mathrm{p}$ & 0.305 & 0.0031 & & & \\
\hline Yml082wp & 0.008 & 0.0001 & Ser1p & 0.043 & 0.0004 & Gus1p & 0.041 & 0.0004 & & & \\
\hline Ymr084wp & 0.019 & 0.0002 & Sno3p & 0.023 & 0.0002 & His4p & 0.093 & 0.0009 & & & \\
\hline Put4p & 0.013 & 0.0001 & Tum1p & 0.015 & 0.0002 & Hom6p & 0.158 & 0.0016 & & & \\
\hline Uga4p & 0.019 & 0.0004 & Uga1p & 0.081 & 0.0008 & Нра3p & 0.116 & 0.0011 & & & \\
\hline Lst4p & 0.012 & 0.0001 & Yhr112cp & 0.014 & 0.0001 & Idh1p & 0.079 & 0.0008 & & & \\
\hline Bap2p & 0.012 & 0.0001 & Yll058wp & 0.008 & 0.0001 & Ilv6p & 0.068 & 0.0007 & & & \\
\hline Avt7p & 0.028 & 0.0006 & Yhr208wp & 0.161 & 0.0016 & $\mathrm{Kgd2p}$ & 0.056 & 0.0006 & & & \\
\hline \multirow[t]{15}{*}{ Ydl119cp } & 0.014 & 0.001 & Alp1p & 0.016 & 0.0002 & Leu4p & 0.041 & 0.0004 & & & \\
\hline & & & Gnp1p & 0.009 & 0.0001 & Lpd1p & 0.011 & 0.0001 & & & \\
\hline & & & Avt4p & 0.009 & 0.0001 & Lys12p & 0.326 & 0.007 & & & \\
\hline & & & $B \operatorname{tn} 2 p$ & 0.021 & 0.0002 & Lys20p & 0.028 & 0.0003 & & & \\
\hline & & & Ssy1p & 0.008 & 0.0001 & Mcm1p & 0.214 & 0.0021 & & & \\
\hline & & & Odc2p & 0.015 & 0.0002 & Met17p & 0.054 & 0.0005 & & & \\
\hline & & & & & & Mis1p & 0.006 & 0.0001 & & & \\
\hline & & & & & & Mmf1p & 0.546 & 0.009 & & & \\
\hline & & & & & & Pro2p & 0.040 & 0.0004 & & & \\
\hline & & & & & & Sam $2 p$ & 0.205 & 0.003 & & & \\
\hline & & & & & & Ser1p & 0.017 & 0.0002 & & & \\
\hline & & & & & & Ser3p & 0.020 & 0.0002 & & & \\
\hline & & & & & & Sfa1p & 0.080 & 0.0008 & & & \\
\hline & & & & & & Shm2p & 0.039 & 0.0004 & & & \\
\hline & & & & & & Ugalp & 0.013 & 0.0001 & & & \\
\hline
\end{tabular}




\section{2. tRNA Aminoacylation for Protein Translation}

Regarding tRNA aminoacylation for protein translation, more specific proteins were identified in the P29 strain than in the G1 strain: 16 proteins versus 3 proteins, respectively (Table 1, Figure 1). The formation of aminoacyl-tRNA (aa-tRNA) is an essential process in protein biosynthesis. Proteins of the aminoacyl-tRNA synthetase family can be classified into two groups, depending on the specificity of amino acids: (i) class I (specific for glutamine, glutamate, arginine, cysteine, methionine, valine, isoleucine, leucine, tyrosine, and tryptophan); (ii) class II (specific for glycine, alanine, proline, serine, threonine, histidine, aspartate, asparagine, lysine, and phenylalanine) [28-31]. At the middle of the second fermentation in the P29 strain, 9 proteins were identified (Aim10p, Cdc60p, Ded81p, Dia4p, Dps1p, Msk1p, Slm5p, Ths1p, and Wrs1p), and at the end of the second fermentation, 7 proteins (Arc1p, Grs1p, Gus1p, Ism1p, Msk1p, Ses1p, and Vas1p) were identified. These proteins are responsible for binding amino acids such as tryptophan (Wrs1p), threonine (Ths1p), asparagine (Ded81p, Slm5p), lysine (Msk1p), aspartate (Dps1p), serine (Dia4p, Ses1p), leucine (Cdc60p), methionine (Arc1p), glutamate (Arc1p, Gus1p), glycine (Grs1p), isoleucine (Ism1p), and valine (Vas1p). These results suggest that yeast may be activating its transcription and translation machinery to try to cope with cell death and autolysis, and they corroborate those previously obtained by our research group [30].

A

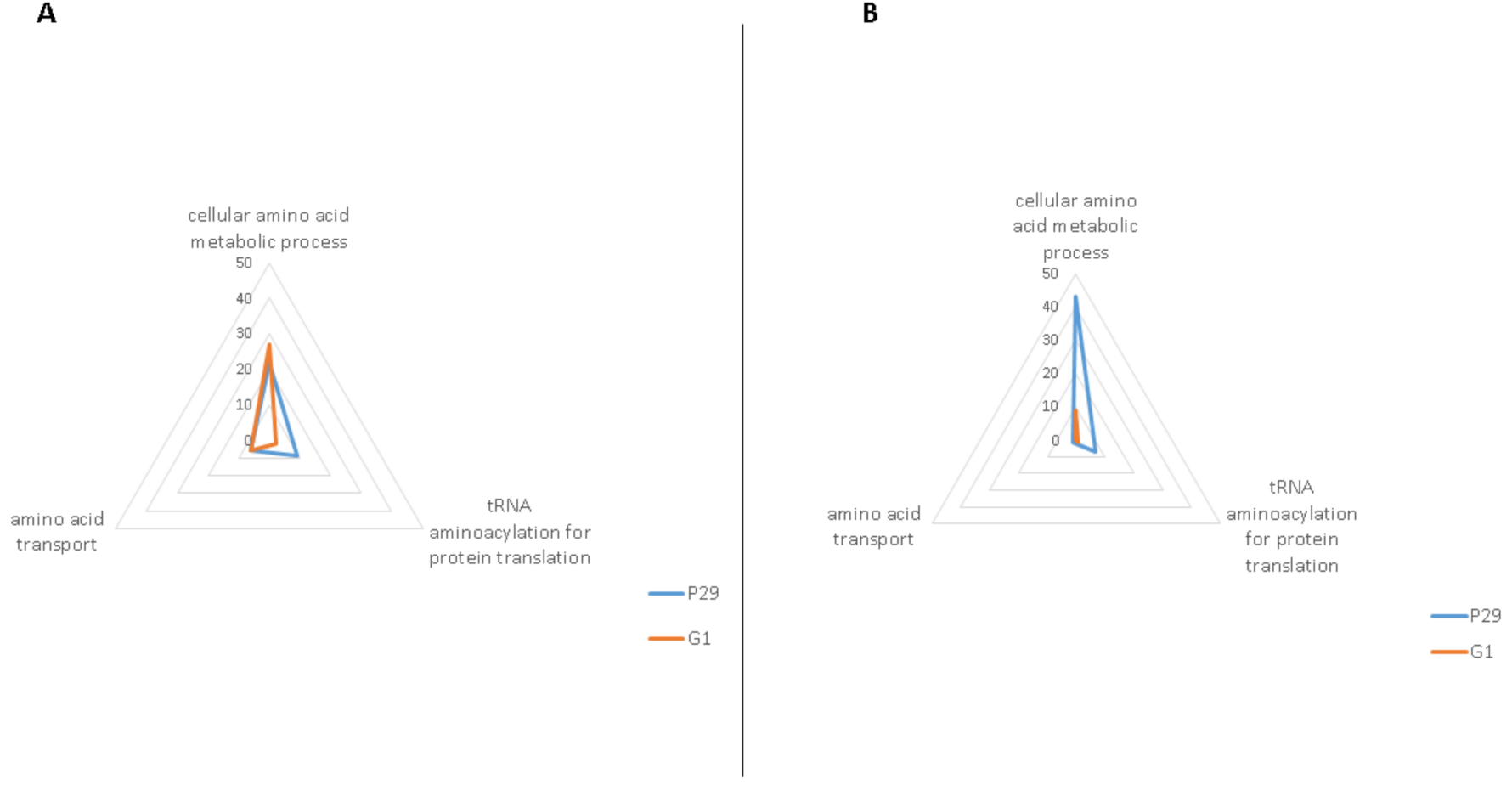

B

Figure 1. Total number of specific proteins related to amino acid metabolism in S. cerevisiae P29 (blue colour) and G1 (orange colour) during two sampling times: at the middle of the second fermentation, MF (A), and at the end of the second fermentation, EF (B).

On the other hand, the specific proteins identified in the G1 strain were Gln4p and Nam2p, which catalyze the binding of glutamine and leucine, respectively, the nuclear protein Pet112p, required to maintain rho $^{+}$mitochondrial DNA [31], and Msm1p; this protein is a mitochondrial methionyl-tRNA synthetase. These results seem to indicate that the protein synthesis machinery in flor yeast (strain G1) is not working, though yeast autolysis may be occurring, which would help the survival of the rest of the population in this harsh condition [32]. 


\subsection{Cellular Amino Acid Metabolic Process}

In the P29 strain, a total of 67 specific proteins related to the cellular amino acid metabolic processes were obtained (24 in MF; 43 in EF), while in the G1 strain, 37 proteins were identified (28 in MF; 9 in EF). Data are shown in Table 1.

The metabolism of amino acids is affected by the pressure the yeast cells are subjected to in the second fermentation, carried out in the bottle, at both levels of the anabolism and catabolism of amino acids. In order to understand the possible interactions between the differential proteins from each strain involved in amino acid metabolism and to provide a better understanding of the $\mathrm{GO}$ terms obtained, a protein-protein interaction network map was created for sampling time (MF, EF) using STRING v11 [18]. Because metabolism is somewhat dynamic, these connections can be conceptualized as networks, and the size and complex organization of these networks present a unique opportunity to obtain a global visualization of the yeast genome during the second fermentation.

\subsubsection{Cellular Amino Acid Metabolic Process at the Middle of the Second Fermentation}

At the middle of the second fermentation, 24 specific proteins in the P29 strain and 28 specific proteins in the G1 strain were identified. These proteins are represented as nodes in Figure 2A,B, respectively. A total of 28 interactions (number of edges) were observed, with a $p$-value of PPI enrichment $<2.23 \times 10^{-12}$ in the P29 strain; while in the G1 strain, 36 interactions were obtained, with a $p$-value of PPI enrichment $<4.44 \times 10^{-16}$; such enrichment indicates that the proteins are at least partially biologically connected as a group.
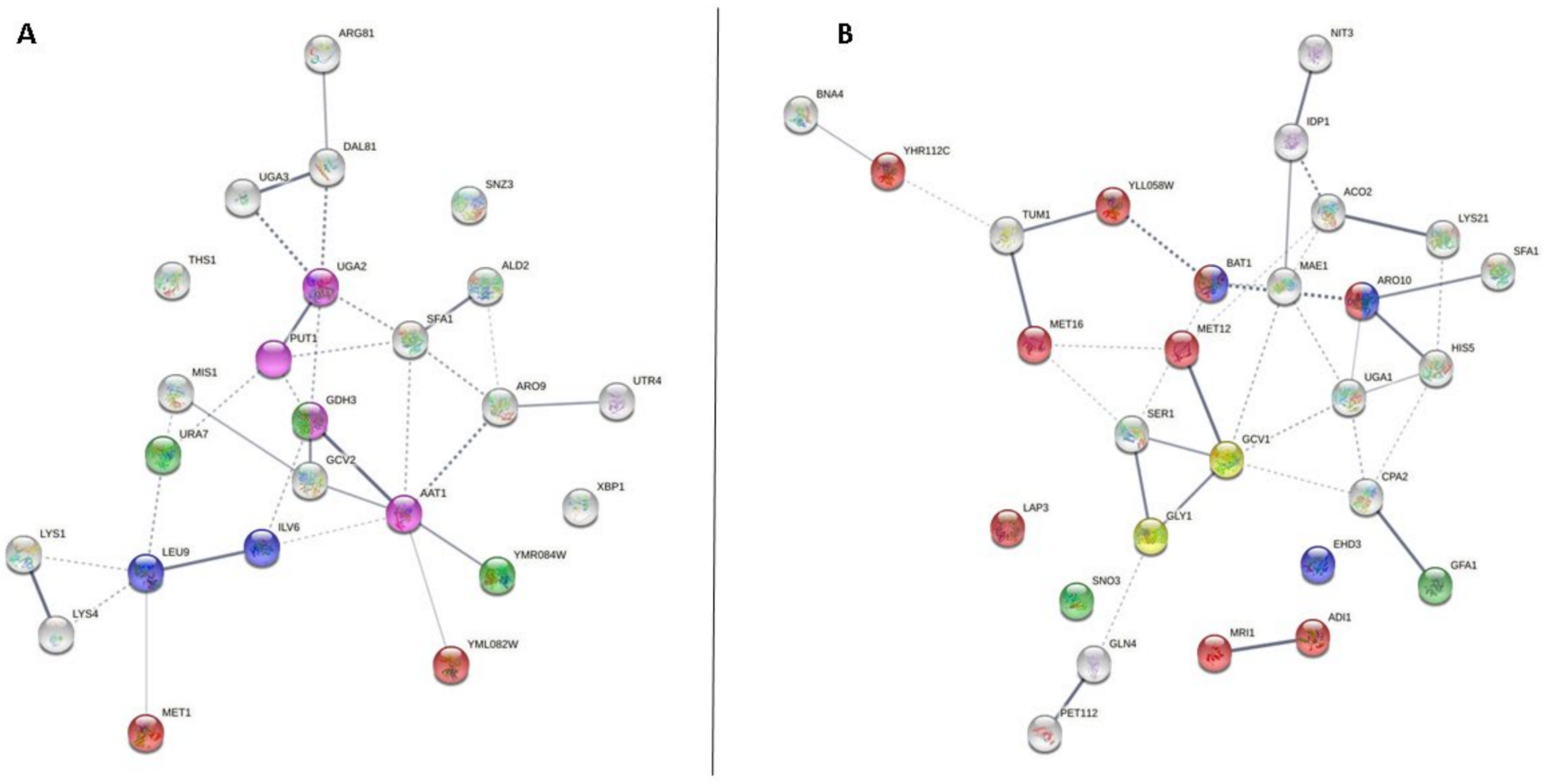

Figure 2. High confidence protein-protein interaction network map built using STRING v11 and based on the proteins of cellular amino acid metabolic process detected in S. cerevisiae P29 (A) and G1 (B) in the middle of the second fermentation. Proteins are shown as nodes, and the existence of interactions between them are represented by lines (the connection between nodes). Line thickness indicates the strength of the different interactions. Nodes with the same color represent specific clusters: sulfur amino acid metabolic process (red nodes), branched-chain amino acid metabolic process (light blue nodes), glutamine metabolic process (light green nodes), glycine metabolic process (yellow nodes), and glutamate metabolic process (light purple nodes).

In the P29 strain, the strongest interactions were observed between proteins belonging to lysine metabolism (white nodes) and the metabolism of branched chain amino acids (dark blue nodes). These amino acids are used for the synthesis of numerous volatile 
aromatic compounds, such as higher alcohols. Furthermore, interactions were obtained between proteins belonging to different GO terms: Gdh3p-Aat1p, Uga3p-Dal81p, and Put1p-Uga2p. The Snz3p, Xbp1p, and Ths1p proteins showed no interaction with the rest of the proteins (Figure 2A). On the other hand, the strongest interactions present in the G1 strain were between proteins belonging to the metabolism of sulfur amino acids, the metabolism of lysine, and the metabolism of glycine. However, most proteins are involved with the metabolism of sulfur amino acids such as methionine and cysteine, which are necessary for yeast growth [33]. Lap3p, Sno3p, and Ehd3p did not show any interaction but were included in different GO terms (Figure 2B). In both strains, the metabolism of lysine was identified. This could be related to an antioxidant response by yeasts [34].

The main difference between both strains in the middle of the second fermentation is glutamate metabolism in the P29 strain and glycine and tryptophan metabolism in the G1 strain. These data are in agreement with the results obtained by Marsit et al. (2016) [6]. These authors reported an increase in the assimilation of various amino acids, particularly glutamate and glycine. Both amino acids are related to the synthesis of most amino acids. Furthermore, the reversible conversion of glutamate to $\alpha$-ketoglutarate is an important branch point between carbon and nitrogen metabolism [6]. In addition, glutamate is one of the nitrogen sources that maintain a high growth rate [35]. During the early stages of fermentation, $S$. cerevisiae rapidly accumulates those amino acids necessary for protein synthesis and formation of volatile compounds such as higher alcohols and their respective ethyl and acetic esters [12], while the surplus is stored in the cellular vacuole, because an amino acid deficit causes a decrease in cell biomass [21]. During the fermentation process, bioactive compounds such as melatonin and serotonin may form because of the tryptophan metabolism, in addition to the higher alcohol tryptophol, which are compounds that have an impact on the sensory properties of the wine [22]. In this case, the identified protein belonging to the tryptophan metabolism, Bna4p $(0.01 \mathrm{~mol} \%)$, is a kynurenine 3-monooxygenase. This protein is required for the de novo biosynthesis of $\mathrm{NAD}^{+}$from tryptophan via kynurenine.

\subsubsection{Cellular Amino Acid Metabolic Process at the End of the Second Fermentation}

At the end of the second fermentation, 43 specific proteins were identified in the P29 strain and 9 specific proteins in the G1 strain. These proteins were represented as nodes in the P29 strain (Figure 3A) and G1 strain (Figure 3B). A total of 234 interactions (number of edges) were observed, with a $p$-value of PPI enrichment $<1.0 \times 10^{-16}$ in the P29 strain, while in the G1 strain, 4 interactions were obtained, with a $p$-value of PPI enrichment $<0.00047$; such enrichment indicates that the proteins are at least partially biologically connected as a group. In view of the results obtained, the P29 strain increased the number of proteins related to the cellular metabolism of amino acids at the end of the second fermentation, unlike the G1 strain.

In the P29 strain, the strongest interactions were observed between proteins belonging to the arginine metabolic process, the sulfur amino acid metabolic process, and the branched-chain amino acid metabolic process; those that obtained a greater number of proteins involved in their respective processes being the metabolism of arginine and sulfur amino acids (cysteine and methionine), 8 proteins in each process. Sulfur in methionine amino acid can be incorporated into cysteine. Furthermore, methionine has been shown to impact oxidative stress resistance and has the potential to be catabolized into $\alpha$ ketoglutarate, which can directly enter the central carbon metabolism, providing additional support for why the demand for cell uptake was high. Glutamate, the most abundant supplemented amino acid, showed the highest uptake yield, and although no directly linked catabolic enzymes were significantly up-allocated, glutamate may be utilized metabolically for other transamination reactions because it is the major amino acid for this role [36]. On the other hand, Bna1p and Mmf1p did not interact with any protein. Bna1p is required for the de novo biosynthesis of NAD from tryptophan via kynurenine, and Mmf1p is required for the transamination of isoleucine. For the branched-chain amino acids (BCAA) 
isoleucine, leucine, and valine and the aromatic amino acids (AAA) phenylalanine, tryptophan, and tyrosine, catabolism, via the Ehrlich pathway, is a way for the cell to salvage nitrogen through transamination reactions [37].

A

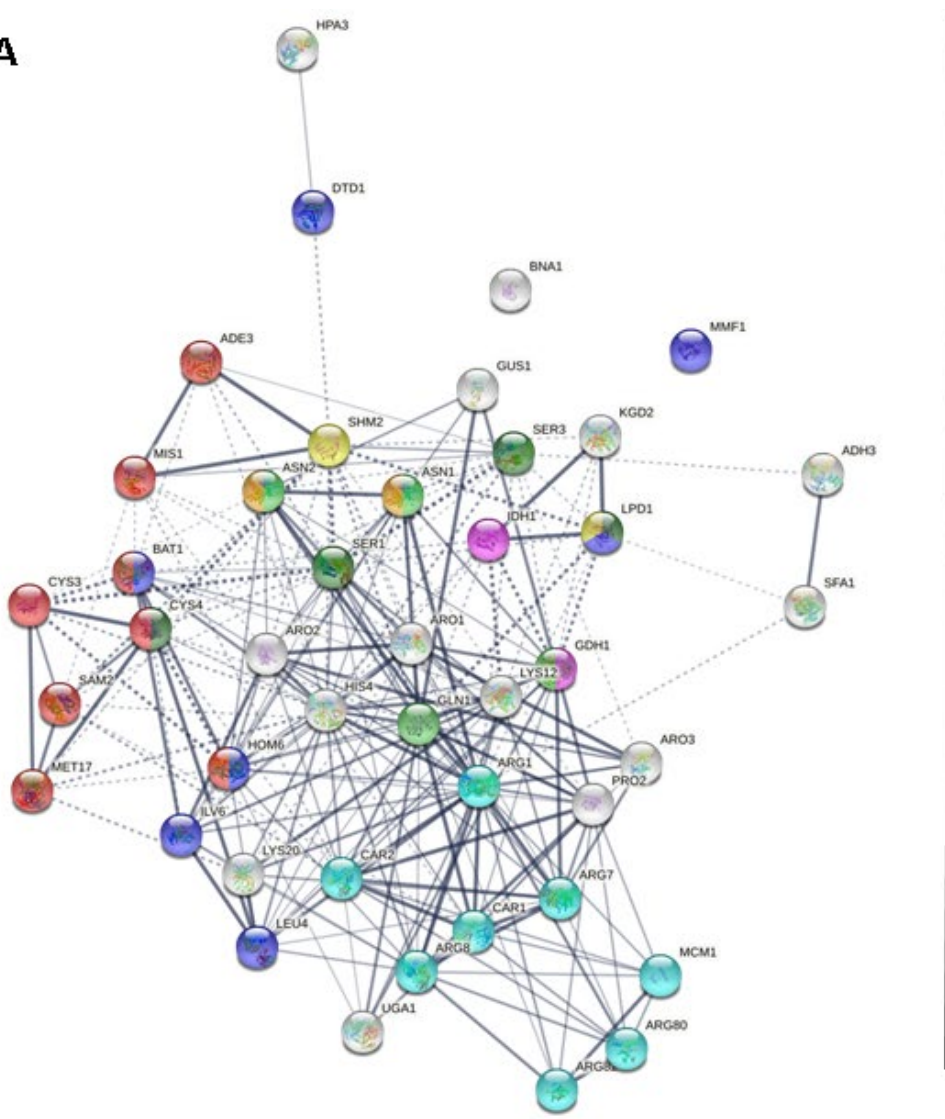

B

Figure 3. High confidence protein-protein interaction network map built using STRING v11 and based on the proteins of cellular amino acid metabolic process detected in S. cerevisiae P29 (A) and G1 (B) at the end of the second fermentation. Proteins are shown as nodes, and the existence of interactions between them are represented by lines (the connection between nodes). Line thickness indicates the strength of the different interactions. Nodes with the same color represent specific clusters: sulfur amino acid metabolic process (red nodes), branched-chain amino acid metabolic process (light blue nodes), glutamine metabolic process (light green nodes), glycine metabolic process (yellow nodes), glutamate metabolic process (light purple nodes), serine metabolic process (dark green nodes), arginine metabolic process (light blue nodes), and asparagine metabolic process (orange nodes).

In contrast, in the G1 strain, this strong interaction was between proteins involved with the glutamate metabolic process. However, Adh5p and Gfa1p did not interact. Adh5p is an alcohol dehydrogenase isoenzyme $\mathrm{V}$ and is involved in ethanol production, while Gfa1p converts fructose-6-phosphate to glucosamine-6-phosphate. This seems to indicate that the yeast is trying to maintain its cell growth and be able to cope with stressful conditions such as overpressure of $\mathrm{CO}_{2}$.

Despite having a different number of proteins, both strains presented amino acids responsible for a high rate of cell growth [20], such as asparagine (P29 strain) and glutamate (G1 strain). Therefore, maintenance of cell viability should be expected in both strains during the second fermentation. The metabolism of these nitrogen compounds depends on the yeast strain, its physiological state, and the physicochemical properties of the wine and fermentation conditions [38]. This difference obtained with respect to the cellular metabolism of amino acids at the end of the second fermentation between both strains could be because they are different strains of yeast: a typical one for the elaboration of this type of wine (P29 strain) and a flor yeast (G1 strain) subjected to unusual $\mathrm{CO}_{2}$ overpressure conditions for this type of strain. This suggests that the G1 strain at the end of 
the second fermentation is stressed, viability is low, and its nitrogen metabolism is strong affected, stopping the biosynthesis of other nitrogenous cellular constituents as well as other compounds formed from its carbon skeleton [10].

The number of identified proteins was higher in the P29 strain compared to the G1 strain, which offered the possibility of establishing a greater number of interactions between these proteins. In both strains, the metabolism of sulfur amino acids, methionine, and cysteine obtained a greater number of proteins involved in these processes: 5 proteins in the P29 strain and 9 proteins in the G1 strain. In strain P29, glutamate metabolism in the middle of the second fermentation and arginine and sulfur amino acids metabolism at the end of the second fermentation stood out; while in the G1 strain, glycine and tryptophan metabolism stood out in the middle of the second fermentation and glutamate metabolism at the end of the second fermentation.

These results represent a first approach in the search for a greater and broader knowledge of the metabolism of yeast during the production of Spanish sparkling wine (cava). However, more research would be necessary, along with a metabolomic study where amino acids are quantified and an assay of enzymatic activities is performed, to reach more solid conclusions. The confirmation of these results by additional tests based on genomic, transcriptomic, and metabolomic activity assays could help achieve a better understanding of the metabolism of amino acids and, therefore, of yeast during the second fermentation in the production of sparkling wines.

Author Contributions: T.G.-M. conceptualized the research, performed experiments, provided resources, and supervised the work; J.M. conceptualized the research, supervised the work, and provided resources; A.P.-P. performed experiments; J.M.-G. participated in the investigation; J.C.M. conceptualized the research, and reviewed and edited the manuscript; M.d.C.G.-J. performed data analysis and wrote the original draft. All authors have read and agreed to the published version of the manuscript.

Funding: This research was granted funding from the "Consejería de Economía, Conocimiento, Empresas y Universidad", Programa Operativo FEDER de Andalucía 2014-2020 (T García-Martínez, J Moreno), Reference 1380480-R.

Institutional Review Board Statement: Not applicable.

Informed Consent Statement: Not applicable.

Data Availability Statement: Not applicable.

Acknowledgments: Kind help of the staff at the Central Research Support Service (SCAI) of the University of Cordoba with the protein analyses is gratefully acknowledged.

Conflicts of Interest: The authors declare no conflict of interest.

\section{References}

1. Mauricio, J.C.; Ortega, J.M.; Salmon, J.M. Sugar uptake by three strains of Saccharomyces cerevisiae during alcoholic fermentation at different initial ammoniacal nitrogen concentrations. Int. Symp. Vitic. Enol. 1993, 388, 197-202. [CrossRef]

2. Moreira, N.; De Pinho, P.G.; Santos, C.; Vasconcelos, I. Relationship between nitrogen content in grapes and volatiles, namely heavy sulphur compounds, in wines. Food Chem. 2011, 126, 1599-1607. [CrossRef] [PubMed]

3. Giudici, P.; Kunkee, R.E. The effect of nitrogen deficiency and sulfur-containing amino acids on the reduction of sulfate to hydrogen sulfide by wine yeasts. Am. J. Enol. Viticult. 1994, 45, 107-112.

4. Barbosa, C.; Mendes-Faia, A.; Mendes-Ferreira, A. The nitrogen source impacts major volatile compounds released by Saccharomyces cerevisiae during alcoholic fermentation. Int. J. Food Microbiol. 2012, 160, 87-93. [CrossRef]

5. Su, Y.; Seguinot, P.; Sanchez, I.; Ortiz-Julien, A.; Heras, J.M.; Querol, A.; Camarasa, C.; Guillamón, J.M. Nitrogen sources preferences of non-Saccharomyces yeasts to sustain growth and fermentation under winemaking conditions. Food Microbial. 2020, 85, 103287. [CrossRef] [PubMed]

6. Marsit, S.; Sanchez, I.; Galeote, V.; Dequin, S. Horizontally acquired oligopeptide transporters favour adaptation of Saccharomyces cerevisiae wine yeast to oenological environment. Environ. Microbiol. 2016, 18, 1148-1161. [CrossRef]

7. Henschke, P.A.; Jiranek, V. Yeast-metabolism of nitrogen compounds. In Wine Microbiology and Biotechnology; Fleet, G.H., Ed.; Harwood Academic Publishers: Langhorne, PA, USA, 1994; pp. 77-164. 
8. Moreno-Arribas, M.V.; Polo, M.C. Amino acids and biogenic amines. In Wine Chemistry and Biochemistry; Springer: New York, NY, USA, 2009; pp. 163-189.

9. Kevvai, K.; Kütt, M.L.; Nisamedtinov, I.; Paalme, T. Simultaneous utilization of ammonia, free amino acids and peptides during fermentative growth of Saccharomyces cerevisiae: Simultaneous utilization of ammonia, free amino acids and peptides. J. Inst. Brew. 2016, 122, 110-115. [CrossRef]

10. Large, P.J. Degradation of organic nitrogen compounds by yeasts. Yeast 1986, 2, 1-34. [CrossRef]

11. Zhong, X.; Wang, A.; Zhang, Y.; Wu, Z.; Li, B.; Lou, H.; Huang, G.; Wen, H. Reducing higher alcohols by nitrogen compensation during fermentation of Chinese rice wine. Food Sci. Biotechnol. 2020, 29, 805-816. [CrossRef]

12. González-Jiménez, M.C.; Moreno-García, J.; García-Martínez, T.; Moreno, J.J.; Puig-Pujol, A.; Capdevilla, F.; Mauricio, J.C. Differential analysis of proteins involved in ester metabolism in two Saccharomyces cerevisiae strains during the second fermentation in sparkling wine elaboration. Microorganisms 2020, 8, 403. [CrossRef]

13. Porras-Agüera, J.A.; Moreno-García, J.; González-Jiménez, M.C.; Mauricio, J.C.; Moreno, J.; García-Martínez, T. Autophagic proteome in two Saccharomyces cerevisiae strains during second fermentation for sparkling wine elaboration. Microorganisms 2020, 8, 523. [CrossRef] [PubMed]

14. Martínez-García, R.; Roldán-Romero, Y.; Moreno, J.; Puig-Pujol, A.; Mauricio, J.C.; García-Martínez, T. Use of a flor yeast strain for the second fermentation of sparkling wines: Effect of endogenous $\mathrm{CO} 2$ over-pressure on the volatilome. Food Chem. 2020, 308, 125555. [CrossRef] [PubMed]

15. Martínez-García, R.; García-Martínez, T.; Puig-Pujol, A.; Mauricio, J.C.; Moreno, J. Changes in sparkling wine aroma during the second fermentation under CO2 pressure in sealed bottle. Food Chem. 2017, 237, 1030-1040. [CrossRef] [PubMed]

16. Bradford, M.M. A Rapid and sensitive method for the quantitation of microgram quantities of protein utilizing the principle of protein-dye binding. Anal. Biochem. 1976, 72, 248-254. [CrossRef]

17. Ishihama, Y.; Oda, Y.; Tabata, T.; Sato, T.; Nagasu, T.; Rappsilber, J.; Mann, M. Exponentially modified protein abundance Index (emPAI) for estimation of absolute protein amount in proteomics by the number of sequenced peptides per protein. Mol. Cell. Proteom. 2005, 4, 1265-1272. [CrossRef] [PubMed]

18. Szklarczyk, D.; Gable, A.L.; Lyon, D.; Junge, A.; Wyder, S.; Huerta-Cepas, J.; Simonovic, M.; Doncheva, N.T.; Morris, J.H.; Bork, P.; et al. STRING V11: Protein-protein association networks with increased coverage, supporting functional discovery in genome-wide experimental datasets. Nucleic Acids Res. 2019, 47, D607-D613. [CrossRef]

19. Bianchi, F.; van't Klooster, J.S.; Ruiz, S.J.; Poolman, B. Regulation of amino acid transport in Saccharomyces cerevisiae. Microbiol. Mol. Biol. Rev. 2019, 83, e00024-19. [CrossRef] [PubMed]

20. Mulero, J.J.; Rosenthal, J.K.; Fox, T.D. PET112, a Saccharomyces cerevisiae nuclear gene required to maintain rho+ mitochondrial DNA. Curr. Genet. 1994, 25, 299-304. [CrossRef] [PubMed]

21. Vilanova, M.; Ugliano, M.; Varela, C.; Siebert, T.; Pretorius, I.S.; Henschke, P.A. Assimilable nitrogen utilisation and production of volatile and non-volatile compounds in chemically defined medium by Saccharomyces cerevisiae wine yeasts. Appl. Microbiol. Biotechnol. 2007, 77, 145-157. [CrossRef]

22. Fernández-Cruz, E.; Álvarez-Fernández, M.A.; Valero, E.; Troncoso, A.M.; García-Parrilla, M.C. Melatonin and derived Ltryptophan metabolites produced during alcoholic fermentation by different wine yeast strains. Food Chem. 2017, 217, 431-437. [CrossRef]

23. Seaston, A.; Inkson, C.; Eddy, A.A. The absorption of protons with specific amino acids and carbohydrates by yeast. Biochem. J. 1973, 134, 1031-1043. [CrossRef]

24. Chianelli, M.S. Sistemas De Transporte De Aminoácidos Neutros En saccharomyces Cerevisiae, Cepas Silvestres Y Mutantes Transporte-Defectivas. Ph.D. Thesis, Universidad de Buenos Aires (Facultad de Ciencias Exactas y Naturales), Buenos Aires, Argentina, 1998.

25. Russnak, R.; Konczal, D.; McIntire, S.L. A family of yeast proteins mediating bidirectional vacuolar amino acid transport. J. Biol. Chem. 2001, 276, 23849-23857. [CrossRef]

26. Tone, J.; Yamanaka, A.; Manabe, K.; Murao, N.; Kawano-Kawada, M.; Sekito, T.; Kakinuma, Y. A vacuolar membrane protein Avt7p is involved in transport of amino acid and spore formation in Saccharomyces cerevisiae. Biosci. Biotech. Bioch. 2015, 79, 190-195. [CrossRef] [PubMed]

27. Kim, Y.; Chattopadhyay, S.; Locke, S.; Pearce, D.A. Interaction among Btn1p, Btn2p, and Ist2p reveals potential interplay among the vacuole, amino acid levels, and ion homeostasis in the yeast Saccharomyces cerevisiae. Eukaryot. Cell. 2005, 4, 281-288. [CrossRef] [PubMed]

28. Delarue, M. Aminoacyl-tRNA synthetases. Curr. Opin. Struct. Biol. 1995, 5, 48-55. [CrossRef]

29. Arnez, J.G.; Moras, D. Structural and functional considerations of the aminoacylation reaction. Trends Biochem. Sci. 1997, 22, 211-216. [CrossRef]

30. González-Jiménez, M.D.C.; García-Martínez, T.; Puig-Pujol, A.; Capdevila, F.; Moreno-García, J.; Moreno, J.; Mauricio, J.C. Biological processes highlighted in Saccharomyces cerevisiae during the sparkling wines elaboration. Microorganisms 2020, 8, 1216. [CrossRef]

31. Eriani, G.; Delarue, M.; Poch, O.; Gangloff, J.; Moras, D. Partition of tRNA synthetases into two classes based on mutually exclusive sets of sequence motifs. Nature 1990, 347, 203-206. [CrossRef] [PubMed] 
32. Porras-Agüera, J.A.; Moreno-García, J.; Mauricio, J.C.; Moreno, J.; García-Martínez, T. First proteomic approach to identify cell death biomarkers in oenological yeasts during sparkling wine production. Microorganisms 2019, 7, 542. [CrossRef] [PubMed]

33. Olin-Sandoval, V.; Shu Lim Yu, J.; Miller-Fleming, L.; Tauqeer Alam, M.; Kamrad, S.; Correia-Melo, C.; Haas, R.; Segal, J.; Peña Navarro, D.A.; Herrera-Dominguez, L.; et al. Lysine harvesting is an antioxidant strategy and triggers underground polyamine metabolism. Nature 2019, 572, 249-253. [CrossRef]

34. Huang, C.W.; Walker, M.E.; Fedrizzi, B.; Gardner, R.C.; Jiranek, V. Hydrogen sulfide and its role in Saccharomyces cerevisiae in a wine-making context. Yeast Res. FEMS 2017, 17, fox058. [CrossRef] [PubMed]

35. Kessi-Pérez, E.I.; Molinet, J.; Martínez, C. Disentangling the genetic bases of Saccharomyces cerevisiae nitrogen consumption and adaptation to low nitrogen environments in wine fermentation. Biol. Res. 2020, 53, 1-10. [CrossRef]

36. Eldarov, M.A. Metabolic engineering of wine strains of Saccharomyces cerevisiae. Genes 2020, 11, 964. [CrossRef] [PubMed]

37. Björkeroth, J.; Campbell, K.; Malina, C.; Yu, R.; Di Bartolomeo, F.; Nielsen, J. Proteome reallocation from amino acid biosynthesis to ribosomes enables yeast to grow faster in rich media. PNAS 2020, 117, 21804-21812. [CrossRef] [PubMed]

38. Mauricio, J.C.; Millán, C.; Ortega, J.M. Influence of oxygen on the biosynthesis of cellular fatty acids, sterols and phospholipids during alcoholic fermentation by Saccharomyces cerevisiae and Torulaspora delbrueckii. World J. Microbiol. Biotechnol. 1998, 14 , 405-410. [CrossRef] 